\title{
Development of Primary Care, Lifestyle Disease and New Elderly Association (NEA) in Japan - Common Philosophy With Hinohara-ism
}

Bando $\mathrm{H}^{1,2}$, Yoshioka $\mathrm{A}^{2,3}$, Iwashimizu $\mathrm{Y}^{4}$, Iwashita $\mathbf{M}^{4}$ and Doba $\mathbf{N}^{5}$

${ }^{1}$ Tokushima University, Japan

${ }^{2}$ Tokushima Division of New Elderly Association (NEA), Japan

${ }^{3}$ The Piano Teachers' National Association of Japan (PTNA), Japan

${ }^{4}$ Division of New Elderly Association (NEA), Life Planning Center Foundation, Japan

${ }^{5}$ Division of Research and Education, Life Planning Center Foundation, Japan

\begin{abstract}
Dr. Shigeaki Hinohara, one of the most eminent physician in Japan lived up to 105, was chairman emeritus of St. Luke's International University and honorary president of St. Luke's International Hospital. He was a pioneer in several fields with remarkable contribution. He introduced and developed primary care (PC) medicine in Japan. The term "life style-related disease" was proposed by him, and decided to use widely by the Ministry of Health and Welfare, Japan. He started New Elderly Association (NEA) to make aged people significant life physically and psychologically with wide spread. He firstly founded Japan BioMusic Association/Japanese Music Therapy Association (JMTA) and developed music therapy in Japan. Thus, by his excellent leadership and management, medical and cultural fields have developed to high degree in Japan.
\end{abstract}

Keywords: Shigeaki Hinohara; Hinohara-ism

Abbreviations: PC: Primary Care; LSRD: Life Style Related Disease; LPC: Life Planning Center; NEA: New Elderly Association; SSA: Smart Senior Association; MT: Music Therapy; NEA: New Elderly Association; SSA: Smart Senior Association; LPC: Life Planning Center; NECM: New Elder Citizen Movement; JBMA: Japan BioMusic Association; JMTA: Japanese Music Therapy Association; MT: Music Therapy; PC: Primary Care; PHC: Primary Health Care; PMC: Primary Medical Care; GP: General Practice; FM: Family Medicine; JMSPC: Japanese Medical Society of Primary Care; JAFM: Japanese Academy of Family Medicine; JSGM: Japanese Society of General Medicine; JPCA: Japanese Primary Care Association; JGFM: Journal of General and Family Medicine; JCMA: Japan Christian Medical Association; ICU: International Christian University

\section{Introduction}

Most eminent physician in Japan, Dr. Shigeaki Hinohara, was died at the age of 105 in July 2017, who was chairman emeritus of St. Luke's International University and honorary president of St. Luke's International Hospital, both in Tokyo. He also received the Order of Cultural Merit from Japan government in 2005 and everyone always respected him as a doctor with supreme personality [1].

On the funeral ceremony, more than 4,000 people and the Empress Michiko attended. Dedication flowers were from the emperor/empress, the crown prince/princess, Mikasa-, Akishino- and Takamado-Imperial branch (Figure 1). Moreover more than 10,000 people came to St. Luke's International Hospital for dedication flowers.

His contribution was remarkable from several points of view. He was the father in Japan for 1) primary care, 2) life style-related disease, 3) New Elderly movement and 4) music therapy. The authors have continued various activities concerning 1-4) with him for long years. By his excellent guidance and management, these medical and cultural fields have developed to high degree in Japan.

In this article, we would introduce the progress and achievement of Dr. Hinohara in each category 1)-4) with some investigation of his activities. Then his broad and deep philosophy called "Hinohara-ism" could be understood, leading to successful aging [2].

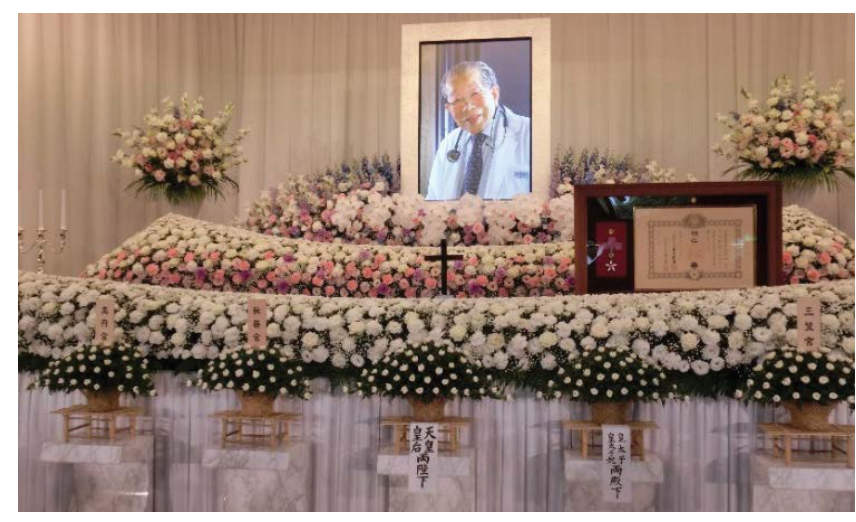

Figure 1: The picture of Dr. Hinohara and the Order of Cultural Merit (2005).

\section{The father of primary care in Japan}

Primary care (PC) covers wide fields, such as primary health care (PHC), primary medical care (PMC), general practice (GP), family medicine (FM), and so on. When Dr. Hinohara studied medicine in United States, he was impressed with PC and introduced the philosophy of PC in Japan. He was a pioneer of complete annual physical checks, "human dry-dock" and also developed preventive medicine and the education system for doctors and co-medicals.

As the concept of PC had been understood and prevalent, Japanese

*Corresponding author: Bando $\mathrm{H}$, Medical Research, Tokushima University, Nakashowa 1-61 Tokushima 770-0943 Japan, Tel: +819031872485; Fax +81886031030; E-mail: pianomed@bronze.ocn.ne.jp

Received September 14, 2017; Accepted September 21, 2017; Published September 28, 2017

Citation: Bando H, Yoshioka A, Iwashimizu Y, Iwashita M, Doba N (2017) Development of Primary Care, Lifestyle Disease and New Elderly Association (NEA) in Japan - Common Philosophy With Hinohara-ism. Prim Health Care 7: 281. doi: 10.4172/2167-1079.1000281

Copyright: ( 2017 Bando $\mathrm{H}$, et al. This is an open-access article distributed under the terms of the Creative Commons Attribution License, which permits unrestricted use, distribution, and reproduction in any medium, provided the original author and source are credited. 
Medical Society of Primary Care (JMSPC) was established in 1978. The author Bando became a member of JMSPC and attended the family practice residency program in United States with frequent continuing consultation with Dr. Hinohara. In 1990's, Bando played the role of the chairman of the International Committee of JMSPC. It had developed to larger society, resulting in newly-foundation of two PC-related medical groups, which are Japanese Academy of Family Medicine (JAFM) and Japanese Society of General Medicine (JSGM).

Merging these three organizations for national-wide movement, Japanese Primary Care Association (JPCA) was founded in 2010 [3]. JPCA has continued variety of activities in PC field, and the current PC concept has been understood widely.

In May 2017, $8^{\text {th }}$ annual congress of JPCA was held, in which Bando was the chairperson with 4,500 attendees [4] (Figure 2). Dr. Hinohara gave us congratulatory address on the first page of the program, at which Dr Hinohara delivered what would become his final greeting at a medical assembly.

In order to honor his achievement, Hinohara Award has been given to excellent doctor every year in the annual congress of JPCA. JPCA has official "Journal of General and Family Medicine (JGFM)". In recent JGFM, common topics include lifestyle, health literacy, health promotion, non-communicable diseases (NCDs) and so on $[5,6]$.

Currently, PC have been indispensable medicine in Japan for

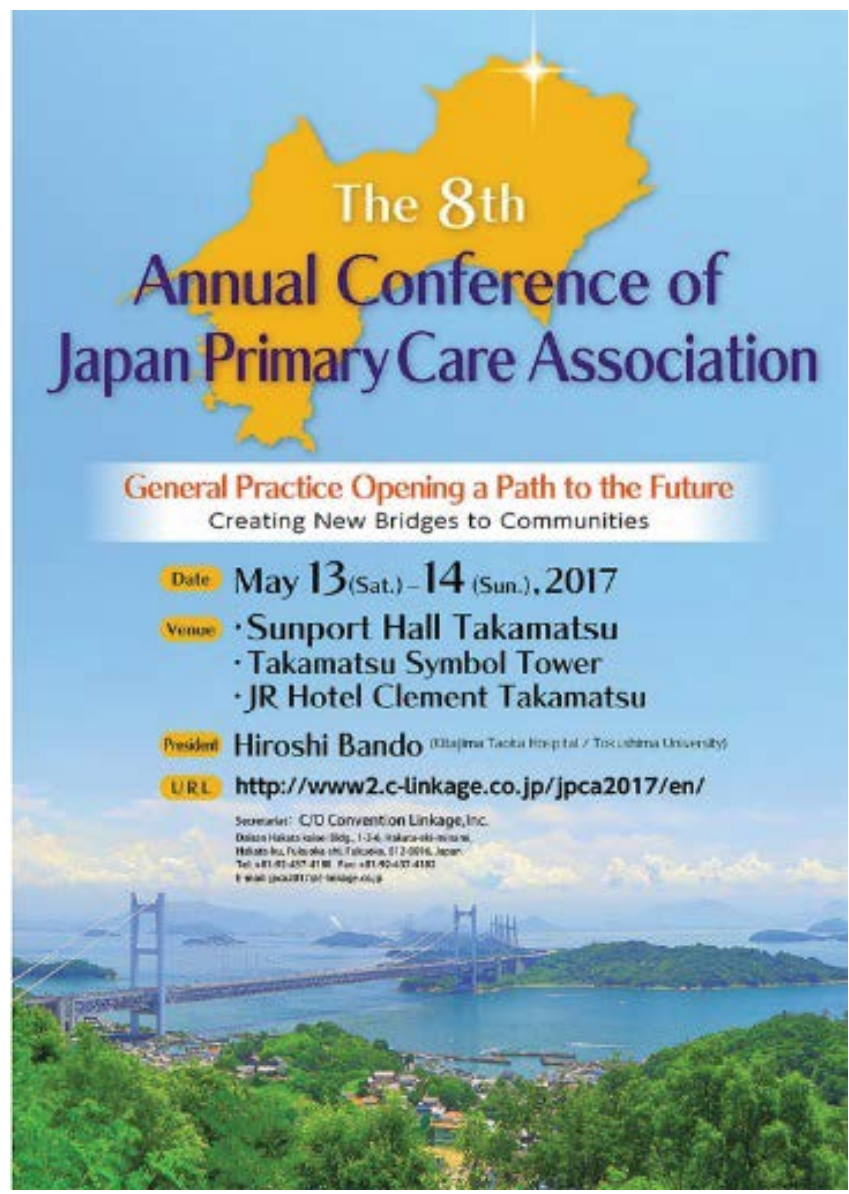

Figure 2: The $8^{\text {th }}$ annual conference of JPCA on May 2017. The Chairperson was Dr. Bando. its ecological predominance $[7,8]$. Thus, it was Dr. Hinohara that introduced and developed PC in Japan, indicating that he would be the Father of Primary Care in Japan.

\section{Life style related disease}

Currently, we usually use the medical term metabolic syndrome (Met-S) including several atherosclerotic diseases such as obesity, hypertension, diabetes mellitus and hyperlipidemia. However, such diseases are formerly called as "adult disease", because adults usually suffer with almost none in young generation. Dr. Hinohara proposed a new term "life style-related disease" in 1978 [9] (Figure 3), which was the first description concerning lifestyle disease in Japan.

Consequently, these diseases increased much in Japan, and the Ministry of Health and Welfare, Japan decided to use "life style-related disease" in 1990's. Author Bando majors in PC and lifestyle diseases including low carbohydrate diet (LCD), exercise therapy and published several reports concerning this field [10-12].

\section{Life Planning Center (LPC) foundation}

In 1939, the Japan Christian Medical Association (JCMA) was established for the missionary medical care by Shigeaki Hinohara and Eiichi Kamiya in Kyoto University. After that, JCMA played the role of health control for staffs and students of International Christian University (ICU) established in 1953.

On the basis of JCMA, the Life Planning Center (LPC) Foundation of Tokyo was established in 1973 as a non-profit foundation by Hinohara who was the chairperson of the board at the LPC and also the honorary director of St. Luke's International Hospital, Tokyo [13,14]. It promoted a healthy quality of life (QOL) for the adult population through holistic and comprehensive strategies to facilitate lifestyle modifications, mainly through health education.

The principle behind all activities at LPC is based on the maxim of Socrates: "It is not living, but living well, in which we ought to consider the most important." The objectives of LPC are 1) to help individuals
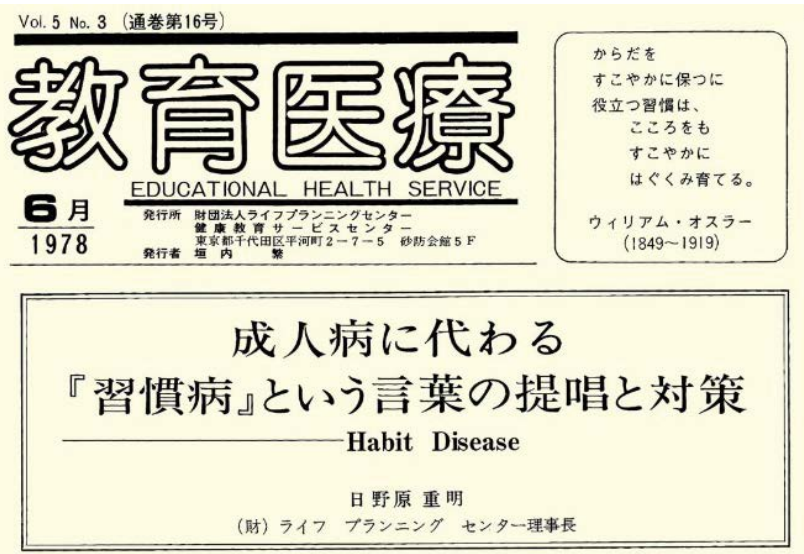

あいまいな成人病のイメージ私は、今まで「成人率の管理」「成人病」の語源をたどると……

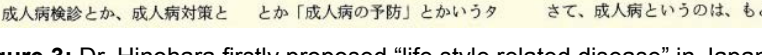

Figure 3: Dr. Hinohara firstly proposed "life style related disease" in Japan.
The Journal of Educational Health Service was launched by Dr. Hinohara, and this is issue of vol.5, No.3, June, 1978 [9]. In the right upper corner, the maxim by William Osler (1849-1919) is described. In the middle portion, the title is "Proposal and counterplan for the new term "life style related disease" as the alternative term of adult disease. 
in gaining an improved awareness and understanding of health, 2) to promote strategies for maintaining and improving one's own mental and physical health by lifestyle changes, 3 ) to assist people in maintaining a high quality of life throughout all of their stages.

LPC have three research fields which are for educational medicine, preventive medicine and new medicine. For example, it has several projects and/or fields such as early detection and treatment of diseases, health support for heart and whole body, clinical psychology, visit nursing station, home care clinic, palliative care, hospice and New Elderly Association (NEA) which is discussed in the following section.

Dr. Hinohara continued clinical medical practice and research in this field with Dr. Doba in life planning center [15,16]. Similarly, Bando to whom Dr.Hinohara has taught for long has researched diabetes [1719]. From August 2017, Dr. Doba has been the director of LPC and managing lots of affairs with Iwashimizu and Iwashita $[13,14]$.

\section{New elderly association (NEA)}

Twenty-one century starts on January, 2001. On September, 2000, LPC started another innovative initiative project which is New Elder Citizen Movement (NECM). It promotes new lifestyles of the elderly according to the concept of successful aging [20]. With this philosophy, the New Elderly Association (NEA) was launched. The object of NEA includes three themes, one mission and five goals [21,22] (Table 1).

At 10 years from establishment, NEA had 11,455 members from all around Japan with 35 local chapters, as well as several non-Japanese nationals living in the United States, Australia, Mexico, Brazil, Korea, Taiwan and other countries. Table 2 showed the increase chapter in NEA and consecutive educational lectures on Jumborees and Forums by Dr.Hinohara until the age of 104 .

NEA has made Smart Senior Association (SSA), in which members can develop mutual communication and bonds by facebook. Dr. Hinohara started using Facebook at the age of 100.
There are 47 NEA local chapters at present in Japan. These chapters always have various program of culture, sports and communication opportunities, such as calligraphy, chorus, computer skills, English conversation, flower arrangement, composing haiku, healthy breathing, hula dancing, listening to classical music, mountaineering, narration, positive thinking conversations, reciting Chinese poems, softball, tennis and so on [23].

Dr. Hinohara and Dr. Doba [24] had continued various research in the anti-aging perspective, such as exercise, hypertension, health promotion, and so on. During lots of activities in NEA, the characteristic lifestyles of the elderly were comprehensively explored by a prospective 5 years cohort study comprising 407 subjects who were registered members of the NEA, resulting some evidence to predict frailty in the elderly [20,24-27].

\section{Music therapy}

Historically speaking, the psychological effect of music has been recognized from ancient times. In United States, the research of music therapy (MT) started for recreation and occupational treatment. Since World War II, MT had been applied to various cases for complementary and alternative medicine.

In Japan, Dr. Hinohara established Japan BioMusic Association (JBMA) on 1986 for development of MT. Research and clinical application of MT were more common in 1990' and Bando held $20^{\text {th }}$ annual congress of JBMA in 1999. To integrate two related associations, Hinohara founded Japanese Music Therapy Association (JMTA) and became the director on 2001 and Bando [28] held $9^{\text {th }}$ annual congress of JMTA with 5800 attendees.

So far, registered music therapists (RMT) have presented various MT sessions and research in medical, welfare and educational fields in Japan [29-31]. Dr. Hinohara himself played the piano, composed music with poem, and he made a musical version of Leo Buscaglia's book [32]. "The Fall of Freddie the Leaf," which was performed in Japan and played Off Broadway in New York.

\begin{tabular}{|c|c|}
\hline \multirow{3}{*}{ Theme } & To love \\
\hline & To initiate \\
\hline & To endure \\
\hline Mission & To transmit the importance of peace and love to children \\
\hline \multirow{5}{*}{ Goals } & To acquire a favourable lifestyle \\
\hline & To maintain an active role in society and close friendships regardless of gender, race or generation \\
\hline & $\begin{array}{l}\text { To maintain hope and faith, cultivate the strength and power to endure any difficulty that one might encounter, maintain and indomitable spirit which should } \\
\text { encompass a deep sympathy for others in difficult situations and extend comfort to people who have lost hope in life }\end{array}$ \\
\hline & To provide loving care for other and feel gratitude to daily life \\
\hline & To be aware that it is never too late to initiate or create something, regardless of age \\
\hline
\end{tabular}

Table 1: The object of New Elderly Assocaition (NEA).

\begin{tabular}{|c|c|c|c|c|c|c|c|c|}
\hline Period & $\begin{array}{l}\text { Japanese } \\
\text { Chapter }\end{array}$ & $\begin{array}{l}\text { Assembly in } \\
\text { Japan }\end{array}$ & $\begin{array}{l}\text { Assembly } \\
\text { attendee }\end{array}$ & Jamboree place & $\begin{array}{l}\text { Jamboree } \\
\text { attendee }\end{array}$ & Forum place & Forum attendee & Hinohara Age \\
\hline 2009.4-2010.3 & 31 & 29 & 36.298 & Hiroshima & 203 & Tokyo & 709 & 98 \\
\hline $2010.4-2011.3$ & 35 & 31 & 33.807 & Tokyo & 1100 & Tokyo & 1100 & 99 \\
\hline 2011.4-2012.3 & 39 & 28 & 34.025 & Mie & 8000 & Tokyo & 1008 & 100 \\
\hline 2012.4-2013.3 & 42 & 28 & 34.434 & Yamaguchi & 1500 & Tokyo & 850 & 101 \\
\hline 2013.4-2014.3 & 44 & 31 & 39.890 & Ehime & 2300 & Tokyo & 1119 & 102 \\
\hline 2014.4-2015.3 & 45 & 21 & 25.640 & Miyagi & 2150 & Saitama & 1200 & 103 \\
\hline 2015.4-2016.3 & 46 & 20 & 21.173 & Nagano & 5028 & Hachioji & 1700 & 104 \\
\hline 2016.4-2017.3 & 47 & 15 & 16.353 & Tokyo & 1,428 & & & 105 \\
\hline
\end{tabular}

Table 2: Various activities of New Edlerly Associations (NEA) during 2009-2017. 


\section{Discussion}

Dr. Hinohara was a pioneer in several fields and was one of the persons who built the foundations of Japanese medicine, which is from Yoshihide Suga, Japan's chief cabinet secretary [1]. He focused the importance of daily life style and usual attitude to how to live well, leading Japan to the world leader in longevity.

Hinohara and Doba [24] showed the research of frailty in which the Canadian Study for Health and Aging-Clinical Frailty Scale (CSHACFS) definition of frailty is applied. It is defined to 7 levels as follows: 1) very fit, 2) well without active disease, 3 ) well with treated comorbid disease, 4) apparently vulnerable, 5) mildly frail, 6) moderately frail and 7) severely frail. It is adequate method to evaluate for instrumental activities of daily living (IADLs), but it is not enough for actual life $[26,33,34]$.

For aged people, cultural health might be defined as a culturally desirable state preferred by society, like the successful aging concept, or combined measures of functional abilities and social participation $[35,36]$. Furthermore, self-efficacy has been recognized as an essential component of well-being which includes health-related quality of life (HRQoL) and social assignment [37].

Concerning self-efficacy, there are 10 related values, which are selfdirection (independence), stimulation, hedonism, achievement, power, security, conformity, tradition (respect for customs), benevolence (preserving and enhancing in-group welfare) and universalism (preserving and enhancing the welfare of all people) [38]. These values reflect the satisfaction of biological needs, demands of coordinated social interaction, and survival and welfare needs of groups.

Formerly 140 masters' athletes were investigated, and 7 factors influenced health esteem, which are constipation, abdominal fullness, insomnia, age, hypnagogic disorder, fatigue-related symptom and forgetfulness [39]. Three factors influenced satisfaction of daily life, which are persistent neurological symptom, age and difficulty in making judgment [39]. Masters' athletes would be the model of anti-aging medicine and be healthy in body and soul. Consequently, these findings may be helpful for speculating the HRQoL for various aged people.

As to the assessment of self-efficacy, we developed a Multiple Choice Questionnaire (MCQ) type test consisting of six questions based on Bandura's original concept $[27,38]$. It seems to be simple, useful and recommended to various investigations.

In summary, this manuscript is to show some of the achievement and contribution of Dr. Hinohara in several fields. He was born in 1911 and his father was a Methodist pastor who had studied at Duke University, which would give large influence on his way of thinking. After family doctor saved his mother's life, he decided to study medicine. When he was flying in 1970, his plane was hijacked and spent four days trapped as one of 130 hostages. Later he said "I believe that I was privileged to live, so my life must be dedicated to other people”.

He has actually continued his life for volunteerism through several axes of activities. Including the spirit and practice of primary health care, broad and deep Hinohara-ism was further developed and accepted for lots of people and would become one of the best philosophy and daily practice world-wide.

\section{Acknowledgement}

We thank all staffs related to various projects for years. We also express our gratitude to other research members at LPC, New Elderly Association, medical group and music therapy.

\section{[Annex] Publication of Dr. Hinohara}

1) Japanese papers, comments and essays

Approximately 6000 published articles are present.

2) Japanese books concerning medicine and others

Dr. Hinohara wrote 400 books.

3) English papers (1940-1977)

He had 58 papers during this period, in which 2 papers in early years are listed [40-41].

\section{4) English papers (1978-2017)}

There were lots of papers during this period. Representative 13 papers are included in the reference [9. 13.15.16. 20, 24, 25, 26, 27, 39] and [42-44].

\section{5) English books}

There are 6 books in English edition until now [45-50]

6) Other Languages

Spanish edition of "Osler's a way of life" was published in 2007 from Fundacion Lilly and Union Editorial (ISBN 978-84-7209-450-5). The Book "Living long, Living good" was already translated and published in Chinese and Korean edition. It will be translated to Vietnamese and Russian edition soon.

\section{References}

1. Roberts S (2017) Dr. Shigeaki Hinohara, longevity expert, dies at (or Lives to) 105. New York Times.

2. Rowe JW, Kahn RL (1987) Human aging: Usual and successful. Science 237: 143-149.

3. Japan Primary Care Association. History of JPCA

4. The $8^{\text {th }}$ Annual Conference of Japan Primary Care Association.

5. Inoue M (2016) Improving quality of care through primary care research. J General Fam Med 17: 267-269.

6. Kudo N, Yokokawa H, Fukuda H, Hisaoka T, Isonuma H, et al. (2016) Analysis of associations between health literacy and healthy lifestyle characteristics among Japanese outpatients with lifestyle-related disorders. J General Fam Med 17: 299-306.

7. Fukui T, Rhaman M, Takahashi O, Saito M, Shimbo T, et al. (2005) The ecology of medical care in Japan. JMAJ 48: 163-167.

8. Fukui T, Rahman M, Ohde S, Hoshino E, Kimura T, et al. (2017) Reassessing the ecology of medical care in Japan. J Community Health 42: 935-941.

9. Hinohara S (1978) A proposal for new term habit disease instead of adult disease. Educ Health Serv 5: 1-2.

10. Bando H (1997) Tokushima diabetic macro-angiopathic research group. Current micro- and macro-angiopathic complication of diabetic patients by primary care physicians on multicenter-study. Jpn J Prim Care 20: 46-51.

11. Bando H, Yoshioka T, Yonei $Y$ Nakamura $T$ (2006) Investigation of quality life in athletes from an anti-aging perspective. Prim Care Jpn 4: 47-51.

12. Bando H, Takenaka $Y$, Nakamura T, Kounoike K, Yonei $Y(2015)$ Investigation for quality of Life (QOL) and self-esteem for health in masters' athletes. Glycative Stress Research 2: 174-181.

13. Doba N (2012) History of study, research and education for 38 years in life planning center (LPC). The life planning center foundation: 1973-2011.

14. Life Planning Center Foundation. Annual Report of LPC No.1-6, 2012-2017.

15. Doba N, Abe H, Hayashida N, Hinohara S (1983) Semi-supervised exercise training program for patients with coronary heart disease - its effectiveness and possible diagnostic implications for predicting their severity. Jpn Circ J 47:735-743.

16. Takagi H, Saiki K, Hinohara S, Doba N, Yanai H, et al. (1991) Construction of life habit inventory. In Methods and applications in mental health surveys: The Todai Health index, ed. Suzuki S and Roberts RE. Tokyo: University of Tokyo Press, pp: 103-121.

17. Bando H, Nakamura T, Yonei Y, Takenaka Y, Seki K (2015) Lipid profile of master's athletes in ice-skating, a model of anti-aging research. Glycative Stress Research 2: 52-57. 
Citation: Bando H, Yoshioka A, Iwashimizu Y, Iwashita M, Doba N (2017) Development of Primary Care, Lifestyle Disease and New Elderly Association (NEA) in Japan - Common Philosophy With Hinohara-ism. Prim Health Care 7: 281. doi: 10.4172/2167-1079.1000281

18. Bando H, Ebe K, Nakamura T, Bando M, Yonei Y (2016) Low Carbohydrate Diet (LCD): Long and short-term effects and hyperketonemia. Glycative Stress Research 3: 193-204.

19. Bando H, Ebe K, Muneta T, Bando M, Yonei Y (2017) Effect of low carbohydrate diet on type 2 diabetic patients and usefulness of M-value. Diabetes Res Open J 3: 9-16.

20. Doba N, Hinohara H, Yanai H, Saiki K, Takagi H, et al. (2011) The new elder citizen movement in Japan. In: Faces of Aging, the Lived Experience of the Elderly in Japan. Matsumoto Y, Ed. Stanford University Press, pp: 36-59.

21. New Elderly Association.

22. Bando H, Ed. Hinohara S. (2011) Let's start for significant life with New Elderly Association. Medical Research Books. Tokushima, Japan.

23. Tomiyama $H$, Hashimoto $H$, Matsumoto $C$, Odaira $M$, Yoshida $M$, et al (2011) Effects of aging and persistent prehypertension on arterial stiffening Atherosclerosis 217: 130-134.

24. Hinohara S, Doba N (2005) The future profile of health promotion and disease prevention in Japan based on the study of seniors over age 75 . Method Inform Med 44: 342-347.

25. Matsubara Y, Hirano M, Doba N, Hinohara S (2008) Life-habits and health status of active Japanese senior citizen: a structured self-check questionnaire study with a special reference to the progress of frailty. Okinawa Wellness Longevity Journal 2008: 1-14.

26. Doba N, Tokuda Y, Goldstein NE, Kushiro T, Hinohara S (2012) A pilot trial to predict frailty syndrome: The Japanese Health Research Volunteer Study. Exp Gerontol 47: 638-643.

27. Yanai H, Doba N, Saiki K, Takagi H, Nishiyama E, et al. (2012) An analysis of aging effects on life habits of Japanese people. In: Statistics and Developmen Issue. Majumder A, Pal M, Ghosh B, et al, Eds. Mittal Publications, New Delhi, pp: 41-97.

28. Bando $H$, Yoshioka A, Nakanishi A (1997) Investigation of ego-gram in music teachers and students. J Jpn Biomusic 15: 152-158.

29. Bando H (2001) Music therapy and internal medicine. Progress in clinical medicine. Asian Med J 44: 30-35.

30. Yoshioka A, Bando H, Yoshioka A (2004) The influence of music experience for the improvement of ego-gram. J Jpn Music Ther 4: 191-197.

31. Yoshioka A, Bando $H$ (2009) Music Therapy Series of Dr. Bando No.2: Psychology. Medical Informatics Service, Tokyo.

32. Buscaglia $L$ (1982) The fall of Freddie the leaf: A story of life for all ages. Slack Incorporated Publisher. ISBN-10: 0943432898.

33. Fried LP, Tangen CM, Walston J, Newman AB, Hirsch C, et al. (2001) Cardiovascular Health Study Collaborative research Group, Frailty in older adults: Evidence for a phenotype. J Gerontol 56: M146-156.
34. Rockwood K, Song X, MacKnight C, Bergman H, Hogan DB, et al. (2005) A global clinical measure of fitness and frailty in elderly people. CMAJ 30: 489495 .

35. Rowe JW and Kahn RL (1999) Active life in old age: Combining measures of functional ability and social participation. DanMed Bull 46: 345-349.

36. Stretton CM, Latham NK, Carter KN, Lee AC, Anderson CS (2006) Determinants of physical health in frail older people: The importance of self-efficacy. Clin Rehabil 20: 357-366.

37. Schwartz SH (1992) Universals in the content and structure of values: Theoretical advances and empirical tests in 20 countries. In Zanna MP (Ed.) Advances in experimental social psychology. London: Academic Press 25: 1-65.

38. Bandura A (1997) Self-efficacy: toward a unifying theory of behavioral change. Psychol Rev 84: 191-215.

39. Doba N, Tokuda Y, Saiki K, Kushiro T, Hirano M, et al. (2016) Assessment of self-efficacy and its relationship with frailty in the elderly. Intern Med 55: 27852792.

40. Hinohara S (1940) Studies of the heart sounds: First Report: A new method for the recording of heart sounds and murmurs. The Nippon J Clin Angio-Card 6:117-121.

41. Hinohara S (1943) Systolic gallop rhythm. Am Heart J 22:726-737.

42. Hinohara S (1992) Free choice of life styles for the aged. Bulletin St. Luke Nurs Univ 18:10-19.

43. Hinohara S (1994) Medicine in Japan, In the Oxford medical companion ed.by Walton J, Barondess J, lock S, Oxford University Press.

44. Hinohara S (1997) Automated multiphasic health testing and services (AMHTS) in Japan -past, present and future. Intern health evaluation association region III Taipei symposium: 41-47.

45. Hinohara H, Niki H (2001) Osler's a way of life \& other addresses, with commentary \& annotations. Duke University Press, Durham \& London. R114.084 2001 610-dc21 200123576.

46. Hinohara H (2006) Living long, Living good. IBC Publishing, Tokyo. ISBN9784-89684-278-4

47. Hinohara $\mathrm{H}$ (2010) To my 10-year-old friends from a 95-year-old me. Fuzambo International, Tokyo, ISBN 978-4-902385-88-5

48. Hinohara H (2010) I want to talk to you Now - about life, time and peace. Japan Broadcast Publishing, Tokyo.

49. Hinohara $H$ (2015) To my young friends, - Let's learn about the constitutions Fuzambo International, Tokyo, ISBN 978-4-905194-91-0.

50. Hinohara $\mathrm{H}$, Baumann $\mathrm{A}$ (2017) Leadership, challenging times: 100 years of wisdom. Fuzambo International, Tokyo, ISBN 978-4-86600-028-2. 